\title{
Use of wireless, ad-hoc networks for proximity warning and collision avoidance in surface mines
}

\author{
Venkata Raghava Siva Naga Shashank Sabniveesu
}

Follow this and additional works at: https://researchrepository.wvu.edu/etd

\section{Recommended Citation}

Sabniveesu, Venkata Raghava Siva Naga Shashank, "Use of wireless, ad-hoc networks for proximity warning and collision avoidance in surface mines" (2015). Graduate Theses, Dissertations, and Problem Reports. 6552.

https://researchrepository.wvu.edu/etd/6552

This Thesis is protected by copyright and/or related rights. It has been brought to you by the The Research Repository @ WVU with permission from the rights-holder(s). You are free to use this Thesis in any way that is permitted by the copyright and related rights legislation that applies to your use. For other uses you must obtain permission from the rights-holder(s) directly, unless additional rights are indicated by a Creative Commons license in the record and/ or on the work itself. This Thesis has been accepted for inclusion in WVU Graduate Theses, Dissertations, and Problem Reports collection by an authorized administrator of The Research Repository @ WVU. For more information, please contact researchrepository@mail.wvu.edu. 


\title{
Use of wireless, ad-hoc networks for proximity warning and collision avoidance in surface mines
}

\author{
Venkata Raghava Siva Naga Shashank Sabniveesu
}

Thesis submitted to the

Benjamin M. Statler College of Engineering and Mineral Resources at West Virginia University in partial fulfillment of the requirements for the degree of

Master of Science

in

Computer Science

Dr. Vinod K. Kulathumani, Ph.D., Chair

Dr. Yaser P. Fallah, Ph.D.

Dr. Roy S. Nutter, Ph.D.

Lane Department of Computer Science and Electrical Engineering

Morgantown, West Virginia

2015

Keywords: Proximity Detection, Wireless Standards, Wireless Sensor Networks

Copyright 2015 Venkata Raghava Siva Naga Shashank Sabniveesu 


\begin{abstract}
Use of wireless, ad-hoc networks for proximity warning and collision avoidance in surface mines

Venkata Raghava Siva Naga Shashank Sabniveesu
\end{abstract}

Despite the record of progress achieved in the United States with respect to reducing fatal and non-fatal injuries in surface mines, both the number and severity of these injuries remain unacceptable. A large fraction of these injuries in surface mines are caused by collisions involving large haulage equipment such as trucks, dozers, and front-end loaders. There are two main contributing factors for these collisions: (i) the massive size of these vehicles, which causes several blind spots surrounding the vehicle for the driver, and (ii) the sheer momentum of these vehicles, which makes it hard to maneuver these vehicles and often necessitates a long response time to avoid collisions. The objective of this work is to investigate the use of different kinds of wireless networks in a distributed ad-hoc mode for providing timely warning about nearby personnel and vehicles, and to evaluate their performance using tests in an actual surface mine.

The contributions of this work are as follows: (i) A zone-based proximity warning system was developed and tested using low power IEEE 802.15.4 radios for detecting obstacles and vehicles at small distances $(<10 \mathrm{~m})$, with the information of the exact zone they are in, around the vehicle. (ii) For timely warning about approaching vehicles at relatively larger distances (10-100m), a GPS system was integrated with Wi-Fi (IEEE 802.11a/b/p) radios in an ad-hoc mode, where information about approaching vehicles can be known as soon as they come into range. A communication range test was performed in an actual surface mine setting to characterize the distances at which the warnings can be reliably received using each of the IEEE 802.11 family of radios. Both the proximity warning system and the Wi-Fi-based collision avoidance system were evaluated for feasibility at an operating surface coal mine in the southern United States. 


\section{Acknowledgements}

I thank my advisor and committee chair, Dr. Vinod K. Kulathumani, for accepting me to work in his lab and guiding me in my research. He has been helpful all the way providing support when in doubt and directing when needed. His educated decisions and intuition helped a lot in shaping this work. I thank Dr. Yaser P. Fallah for helping with the equipment needed for the evaluation of wireless standards task. I am glad that Dr. Roy S. Nutter promptly responded to my request to be a part of my committee.

The works of people who, in the spirit of fellow human beings, let, for free and fair use, their knowledge, software implementations and documentations without which this and succeeding works would be taking massive amounts of time and repetitive effort to be done, are hereby being acknowledged to have aided this work. Technical discussions with a few of these real people have been very educative and helped speed up tasks that made up this work.

When a quick introduction to a concept was required or extensive periods of their lives were needed to help me setup the experiments and collect data required for this work, $\mathrm{Mr}$ Rahul Kavi, Mr Ajay Krishna Teja and Mr Bisleshana Brahma Prakash have been very supportive. Mr Osman Gani, an advisee of Dr Fallah has been helpful throughout the wireless standards evaluation task by pointing to necessary software and advising about additional equipment needed. I would remain glad for having Mr Masahiro Nakagawa, Mr Priyash Varma and Mr Rohit as my labmates for the informative discussions I had with them that helped me appreciate different concepts from various fields adjoining Computer Science.

I am thankful to my friends outside the lab for being with me when I'm out and needed myself badly. I thank my parents for supporting my decision to pursue Computer Science and Engineering which encouraged everything that is getting declared here. 


\section{Contents}

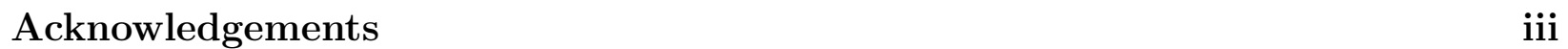

List of Figures $\quad$ vi

List of Tables $\quad$ vii

1 Introduction $\quad 1$

1.1 Overview . . . . . . . . . . . . . . . . . . . . 1

1.2 Summary of Contributions . . . . . . . . . . . . . . . . . . . . . 2

1.3 Organization of rest of the thesis . . . . . . . . . . . . . . . 3

2 Background work and existing literature $\quad 4$

2.1 Applications of sensor networks . . . . . . . . . . . . . . . . . . 4

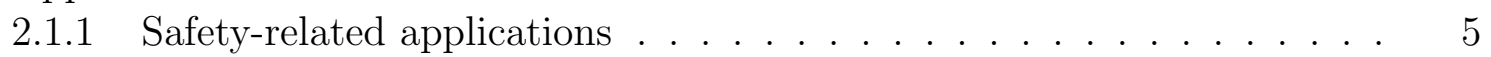

2.1.2 Proximity detection . . . . . . . . . . . . . . . . . 6

2.2 Quality estimation of wireless standards . . . . . . . . . . . . . . 8

2.2.1 An overview of wireless standards[3][4][5] . . . . . . . . . . . 8

2.3 New aspects of this work . . . . . . . . . . . . . . . . . . . 11

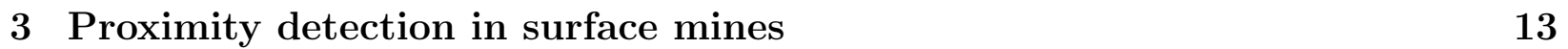

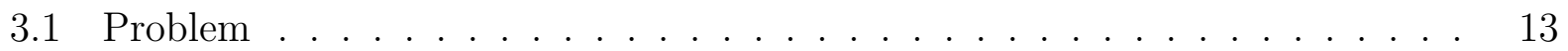

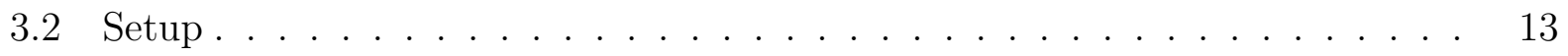

3.3 Initial testing and final deployment . . . . . . . . . . . . . . . 15

3.4 Results . . . . . . . . . . . . . . . . . . . . 16

4 The wireless standards evaluation in surface mines 19

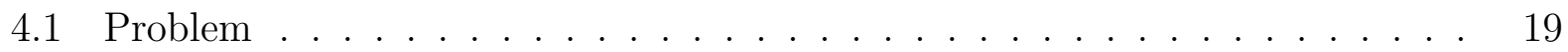

4.2 Setup . . . . . . . . . . . . . . . . . . . . 22

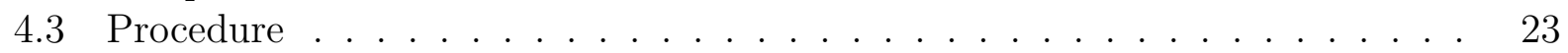

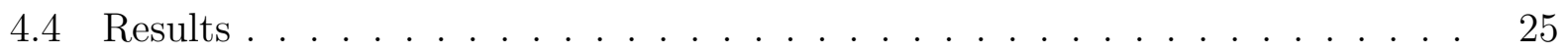

5 Conclusion and Future work $\quad 30$

5.1 Conclusion . . . . . . . . . . . . . . . . . . . . . . 30

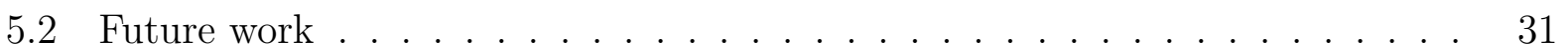


$\begin{array}{ll}\text { References } & 32\end{array}$ 


\section{List of Figures}

3.1 TelosB mote . . . . . . . . . . . . . . . . . . . . . . . . . 14

3.2 Schematic division of zones around a truck . . . . . . . . . . . . 15

3.3 Structure of the packet used in the proximity detection sytem . . . . . . 16

3.4 Possibility of determining zone information for various distances between sender and truck . . . . . . . . . . . . . . . . . 17

3.5 Accuracy of the proximity detection system tested at distances - $3 \mathrm{~m}, 6 \mathrm{~m}$ and

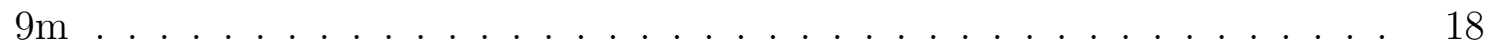

4.1 (On left) mud pile causing hidden line of sight. (On right) sloped terrain. . 20

4.2 Components used for wireless standards evaluation in surface mines . . . . . 22

4.3 Median packet reception rate as a function of sender-receiver distance (direct

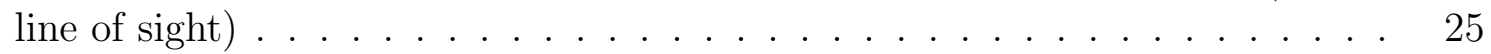

4.4 RSSI trend as a function of sender-receiver distance (direct line of sight) . . 25

4.5 Median packet reception rate as a function of sender-receiver distance (hidden

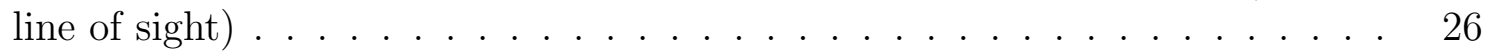

4.6 RSSI trend as a function of sender-receiver distance (hidden line of sight) . . 26

4.7 Median packet reception rate as a function of sender-receiver distance (receiver at the top of incline $) \ldots \ldots \ldots \ldots \ldots$. . . . . . . . . . . . 27

4.8 RSSI trend as a function of sender-receiver distance (receiver at the top of

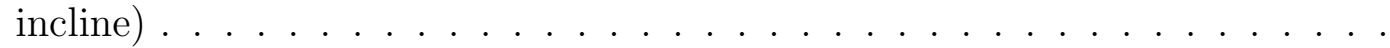

4.9 Median packet reception rate as a function of sender-receiver distance (receiver at the bottom of incline $) \ldots \ldots \ldots \ldots$

4.10 RSSI trend as a function of sender-receiver distance (receiver at the bottom

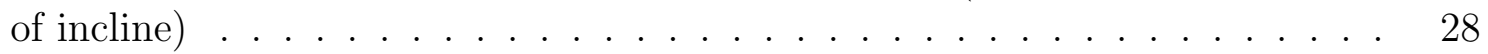




\section{List of Tables}

4.14 locations where wireless standards evaluation was conducted . . . . . . . . 24

4.2 Average distance at which more than $75 \%$ packets are received under different topological conditions in surface mines for each of the three radios . . . . . . 


\section{Chapter 1}

\section{Introduction}

In this chapter, the problem of safety in surface mines and the applicability of wireless sensor networks to it is explained. The motivation to perform an analysis of the quality of different wireless standards in the surface mines is presented. A brief overview of the systems developed and tests conducted is discussed.

\subsection{Overview}

Despite the record of progress achieved in the United States with respect to reducing fatal and non-fatal injuries in surface mines, both the number and severity of these injuries remain unacceptable. A large fraction of these injuries in surface mines are caused by collisions involving large haulage equipment such as trucks, dozers, and front-end loaders[1]. There are two main contributing factors for these collisions: (i) the massive size of these vehicles, which causes several blind spots surrounding the vehicle for the driver, and (ii) the sheer momentum of these vehicles, which makes it hard to maneuver these vehicles and often necessitates a long response time to avoid collisions[2]. The objective of this work is to investigate the use of different kinds of wireless networks in a distributed ad-hoc mode for providing timely warning about nearby personnel and vehicles, and to evaluate their performance using tests in an actual surface mine. 


\subsection{Summary of Contributions}

This work examines the feasibility of utilizing a proximity detection system to enhance safety in a vehicular environment while aiming to be low-cost, easily-deployable, quicklyreconfigurable and simple-to-use. To detect the vehicles moving at larger distances in vicinity, the exchange of information from Global Positioning System(GPS)-based systems in vehicles operating in surface mines [6] can make use of wireless communication technologies. With the growing interest towards new communication protocols targeted at vehicular networks, a reliable test of the reliability of different 802.11 wireless standards serves the purpose of informing the adopters of such communication infrastructure for the purposes of safety.

Design of IEEE 802.15.4 radios-based proximity zoning for near-field objects: The goal of this system is to provide a warning to a vehicle operator when another equipment or personnel comes close and also to accurately determine the location as one of several zones around the vehicle. For areas that are closer to the equipment, GPS data is not precise enough to provide a location indicator. Hence an RF based system was considered. The Telos platform[7] which consists of a 2.4GHz IEEE 802.15.4 radio was used for the development of a proximity detection system. The well-known operating system for embedded platforms TinyOS was used to program the motes. The system would constantly monitor the wireless transmissions being broadcasted around and when a marker mote approaches, based on the signal strengths sensed by all the four motes surrounding the vehicle, it is estimated to be in one of the eight zones, in real-time. The system was tested with the detection reported for each second when the packet rate was 5 per second. The detection rate and the transmission frequencies are easily modifiable in the program before deployment. This system was tested when a subject was moving at distances (1) 3m, (2) 6m, (3) $9 \mathrm{~m}$ and (4) $12 \mathrm{~m}$ which are considered good enough to be considered a safe distance from the huge mining vehicles.

Characterization of $802.11 \mathrm{a} / \mathrm{b} / \mathrm{p}$ radios in ad-hoc mode for communication: For timely warning about approaching vehicles at relatively larger distances (10-100m), a GPS system can be integrated with Wi-Fi based communication. The use of an ad-hoc mode for Wi-Fi networks avoids the need for a cellular or long-range multi-hop network where GPS data would first be transmitted to a central processing unit and the vehicle locations 
would be then broadcast from that central system. Instead, in the proposed approach, information about approaching vehicles is known as soon as they come into communication range of each other. The comparative study of well-established and rising wireless standards IEEE 802.11a, IEEE 802.11b and IEEE 802.11p(Wireless Access in Vehicular Environments) presents the trends in deterioration of packet rates for distances upto $300 \mathrm{~m}$. This study has been carried out in 4 different regions of surface mines the cases being - (1) direct line of sight, (2) hidden line of sight, (3) receiver at the top of incline and (4) receiver at the bottom of incline. The approximate distances at which the transmissions start becoming unreliable with the packet reception rates dropping below $75 \%$ have been reported for each standard in each scenario. A case-by-case comparison of trends for all wireless standards in each scenario is visually depicted to be able to draw conclusions. This work systematically investigates the packet reception characteristics and the received radio signal strength at different source-destination distances for IEEE $802.11 \mathrm{a}, \mathrm{b}$, and p radios, inside an actual surface mine.

Additionally, in order to facilitate collection of long term data about locations of different vehicles, a cloud-based data logging system was tested. This system could potentially be used to collect data from any sensor installed on the truck, which in our case is a GPS system that tracks the location of trucks.

\subsection{Organization of rest of the thesis}

The remaining part of this document is arranged as follows: Background information and existing literature is covered in the 2 nd chapter. The design, procedure and outcomes of the Proximity Detection System and the study of different wireless standards is presented in the 3rd chapter. In 4th chapter, the results and succeeding analysis are provided. In 5th chapter, suggestions are made for extensions of this work in the future. 


\section{Chapter 2}

\section{Background work and existing literature}

This chapter examines the existing research work in the area of sensor networks, proximity detection with the goal of safety in surface mines. An overview of the wireless standards considered in this work is mentioned and the procedures considered for quality estimation of various wireless standards are then discussed. At the end, the important aspects that differentiate this work from others are provided.

\subsection{Applications of sensor networks}

The use of wireless sensor networks for environmental monitoring is well established. Automated local Evaluation in Real-Time[8][9], a system developed by National Weather Service in 1970s is one such system that is in use in real-world to detect natural hazards such as earthquakes, cyclones, tsunamis etc. in California and Arizona.

Ning Xu's[10] work addresses the habitat-monitoring aspect of sensor networks. The cited application - Great Duck Island(GDI) system[11] observes the nesting patterns and changes in environmental parameters during breeding season for Leach's Storm Petrel birds. The system additionally monitors the temperature, humidity and other environmental factors from the deployed environment and transmits it to a central base station for further analysis by researchers. 
The above applications cover a wide range of area with hundreds of sensor nodes deployed that function autonomously and communicate with base stations to forward collected raw sensor data to processing centers for further analyses.

The Center for Information Technology Research in the Interest of Society (CITRIS) of Berkeley demonstrated the application of the Smartdust motes to monitor and thereby reduce the consumption of electrical energy in the buildings of University of California, Berkeley[12]. The system completely utilized the TinyOS[13] operating system to power the motes. The same TinyOS programming environment has been used extensively in the current work on proximity detection system.

\subsubsection{Safety-related applications}

The area of Structural Health Monitoring in safety tasks sees a lot of wireless sensor network applications such as measuring vibrations to establish the safety of civil structures like bridges, buildings etc.[14].

Researchers in china developed a wireless sensor network for monitoring methane gas diffusion in underground mines. The proposed Heterogeneous Hierarchical Mine Safety Monitoring prototype system(HHMSM) [15] has the motes equipped with gas sensors that sample the methane concentration periodically and transmit to the monitoring server. Surface mines do not see a problem of gas leakages as much as their underground equivalents do but with huge equipment moving around the workers, a different problem of collisions exists.

Intelligent Transportation Systems(ITS) is the name given to a collection of systems which utilise information and communication technologies to support transport by aiding related infrastructure, mobility and traffic management and more. The idea of utilizing wireless sensor networks for preventing vehicle collisions is demonstrated in one such work[16] where the investigator proposes an ad hoc solution to avoid unsafe overtaking in two-way single carriageway routes, concentrating on rural areas. Each vehicle is equipped with a magnetic sensor and an accelerometer sensor including a GPS receiver in order to help the driver by alerting about unsafe overtaking, especially in difficult visibility conditions such as foggy weather etc. 


\subsubsection{Proximity detection}

Magnetic sensors placed externally on roadside have been used to calculate the velocity and location of a vehicle passing close to them in order to predict collisions near intersections[17]. The disturbance in earth's magnetic field due to the presence of a vehicle is sensed and the resulting voltages are processed and then wirelessly transmitted to a base station for further processing.

Given the importance of the collision problem in surface mines, there has been extensive research in the past decade on proximity warning technologies for vehicles[18][19][20][21] [22]. A summary of these ideas is provided below:

Ultrasonic sensors: Ultrasound devices typically operate at $40 \mathrm{KHz} 250 \mathrm{KHz}$ and emit a short burst of ultrasonic waves, which are reflected back when they hit a hard surface[23]. The echo time is then used to estimate distances of obstacles. However, ultrasound systems require direct line of sight and any object in their path will cause a proximity alarm. This is likely to cause false alarms. Moreover, the range of these devices is typically very short $(<10 \mathrm{~m})$. As a result, these sensors are typically used for parking assistance in regular vehicles, but they are mostly unsuited for proximity warning in large surface mine vehicles.

Pulsed radar and LIDAR based systems: Radars[24] and Lidars[25] are two other promising technologies that have been used for proximity warning. They operate similarly, in concept, as ultrasound echoing, but have a larger range and are much more accurate in distance measurements. However, they also suffer from false alarm issues as they can get triggered by the detection of any obstacle in their path. For example, on large trucks, they can get blinded by obstacles such as the large tires or large dumps of dirt and rocks. There are also chances of missed detections for example, when personnel walk directly under their field of view, they remain undetected[24][26]. Moreover, these systems are often expensive, and installing them on surface mine trucks that operate in rugged environments is quite challenging.

Camera based systems: Advances in computer vision with respect to object recognition have led to the use of cameras for detecting collisions in vehicles[22][18][27]. However, camera-based systems depend upon adequate lighting and do not perform well in the pres- 
ence of fog, dust, and dirt on the lenses. Moreover, when multiple cameras are used, reliable pattern recognition algorithms are needed to point accurately to an obstacle and present the correct view on a terminal; it is not feasible for a driver to shift through multiple screens all the time. Designing such reliable systems are challenging. Therefore, cameras are typically used as complementary systems to other proximity detection technologies; for example, if an obstacle is detected by a radar in a given direction, the camera view from that side is projected on the terminal.

RFID and electronic tag-based systems: The key idea in these systems is that devices that are embedded on vehicles and personnel periodically emit electromagnetic waves. These devices can also sense signals transmitted by other devices, and when devices are close enough, the signal strength is enough to cause a proximity alarm. These systems are easy to deploy, do not depend on line of sight and typically have a range of 12-18m (40-60 feet). But existing systems are typically designed only to detect the presence of other vehicles or personnel in the nearby vicinity and not to pinpoint a location or direction[28]. One of the systems that we designed here is also an RF-based proximity warning system that uses IEEE 802.15.4 radio operating the $2.4 \mathrm{GHz}$ frequency. However, we show how multiple RF devices embedded on the truck, along with the received radio signal strength indicator on the radios, can be used to accurately identify the zone surrounding the vehicle in which an obstacle is detected.

GPS based systems: GPS devices can provide location estimates with an accuracy of 3-4m (about 10 feet). Therefore, GPS devices along with some form of wireless communication are increasingly being used for detecting approaching vehicles and for collision avoidance[29][30][31][32][33]. In this work, we have used a GPS-based system for collision detection from larger distances $(>10 \mathrm{~m})$. At very close distances, the GPS systems are not accurate enough to correctly estimate the direction in which a nearby obstacle has been detected, although they can estimate that there is an object nearby. Therefore, for closer distances, we have used an RF-based system. Secondly, as noted earlier, some form of wireless communication is needed so that GPS locations of nearby vehicles and objects can be communicated to other approaching vehicles. For this work, we evaluated three Wi-Fi based standards in an actual surface mine setting to understand their effectiveness in communi- 
cating the locations from a sufficient distance such that there is enough time for drivers to react.

\subsection{Quality estimation of wireless standards}

With the goal to implement a GPS-based proximity warning system, tests were conducted to understand the performance of different wireless standards usable. The idea is that trucks should exchange GPS coordinates when they approach one another, using some form of wireless communication to provide updates about the location of one to other vehicles. These updates can be provided in two ways: (i) a centralized cellular or long-range communication infrastructure can be used to communicate data from each vehicle to a processing center and then re-broadcast data from there to all the vehicles. (ii) a decentralized peer-to-peer manner may be adopted so that only vehicles that are nearby would communicate. The former approach is more cumbersome and expensive: it involves excessive setup costs in surface mines as well as high cost for data usage. in this work, we used the latter mechanism by utilizing IEEE 802.11 (Wi-Fi) radios in an ad-hoc mode. In this mode, two Wi-Fi radios can communicate with each other as soon as they come within communication range of each other.

\subsubsection{An overview of wireless standards[3][4][5]}

The Institute of Electrical and Electronic Engineers (IEEE) makes and maintains standards affecting a wide range of industries. The Wi-Fi Alliance defines Wi-Fi as a wireless local area network (WLAN) product based on the IEEE 802.11 standards. IEEE 802.11 is a set of media access control (MAC) and physical layer (PHY) specifications for implementing wireless computer communication in the $2.4,5$, and $60 \mathrm{GHz}$ frequency bands. The IEEE 802.11 family consists of a series of standards that use different modulation techniques and frequency bands, but use the same underlying communication protocol. After the publication of a standard, a Task Group(TG) is created for the creation of each relevant proposed amendment. These amendments are denoted by a non-capitalized letter and are supposed to be made part of the original standard in its next revision. The IEEE 802.11 is the working 
group(WG) dedicated to Wireless LAN and Mesh networks. This working group revises wireless standards from time-to-time while combining the amendments made to previous standard. To put it in concrete terms, we today have five IEEE 802.11 standards, suffixed with the years they were published

1. 802.11-1997 (also known as 802.11 legacy the original)

2. 802.11-2003 (combines amendments a, b and d)

3. 802.11-2007 (combines amendments e, g, h, i and j)

4. 802.11-2012 (combines amendments k, n, p, r, s, u, v, w, y and z)

5. 802.11-2016 (anticipated; combines amendments aa, ae, af, ac and ad)

In this work, we concentrate on the IEEE $802.11 \mathrm{a}$, b, and p series for evaluation.

802.11a: Originally IEEE 802.11a-1999, this amendment defines these requirements: $5 \mathrm{GHz}$ band operation, Orthogonal Frequency Division Multiplexing(OFDM) based air interface for signal modulation, $1.554 \mathrm{Mbit} / \mathrm{s}$ data rate. The $802.11 \mathrm{a}$ specification is an amendment to the IEEE 802.11 family that uses the same frame format and link layer protocol as the original 802.11 specification.

\section{Benefits:}

1. In practice, fewer devices operate in 802.11a and hence those that do have a significant advantage that their channels of communication are less crowded.

\section{Drawbacks:}

1. The effective range is less when compared to $802.11 \mathrm{~b}$ and $802.11 \mathrm{~g}$ since small wavelengths get absorbed by solid objects in their path and cannot penetrate through walls.

2. Path loss in signal strength is proportional to the square of signal frequency which implies that 802.11a transmissions suffer great loss. 
802.11b: Originally IEEE $802.11 b-1999$, this is the widely accepted amendment in the consumer market due to its high throughput. The maximum data rate is $11 \mathrm{Mbit} / \mathrm{s}$ and it operates in the $2.4 \mathrm{GHz}$ band. The 'Adaptive Rate Selection' allows $802.11 \mathrm{~b}$ devices to switch between different modulation techniques, depending on the re-broadcasts resulting form errors. Commonly referred to as Direct-Sequence Spread Spectrum(DSSS), the modulation technique covers 3 variants[34][35]:

1. Complementary Code Keying (CCK) offers 5.5 Mbps/11 Mbps

2. Differential Quadrature Phase Shift Keying (DQPSK) works for larger distances than the above, offers $2 \mathrm{Mbps}$

3. Differential Binary Phase Shift Keying (DBPSK) works for larger distances than the above, offers 1 Mbps

\section{Benefits:}

1. Better throughput along with substantial reduction in prices of supporting equipment led to wide adoption and hence is a popular standard in the consumer market.

\section{Drawbacks:}

1. The $2.4 \mathrm{GHz}$ band is generally very crowded owing to its widespread usage

2. Additionally, many consumer devices such as microwave ovens, cordless telephones, etc. can interfere with signals in this band.

However, in mining environments, we do not expect this interference.

802.11p: Originally IEEE 802.11p-2010, this standard is specifically targeted for use in vehicular communication systems under the name 'Wireless Access in Vehicular Environments'(WAVE). The maximum data rate is $11 \mathrm{Mbit} / \mathrm{s}$ and it operates in the range 5.850-5.925 GHz. The modulation scheme used is OFDM - Orthogonal Frequency Division Multiplexing and the data rate can range from 6 to $27 \mathrm{Mbps}[36]$. The medium access control (MAC) layer functionality is slightly modified to include provision for rapid communication of DSRC devices with no need for authentication or authorization processes as in the original 802.11 standard. 


\section{Benefits:}

1. Being specifically reserved for vehicular communications, the $802.11 \mathrm{p}$ band stays less crowded and readily available for vehicles to form networks quickly in an ad-hoc manner.

\section{Drawbacks:}

1. Its very short range $(\approx 300 \mathrm{~m})$ makes it suitable only for vehicles to communicate for a short-time on the road

\subsection{New aspects of this work}

This section describes contributions of this work compared to the existing research work.

The works mentioned above use specialized sensors such as magnetometers[16] or radars[24] for detecting proximity and then, being wireless sensor networks, utilize wireless transmissions to communicate the data to a base station. The system developed here involves no special sensors than the wireless transmissions themselves. Every receiver of a wireless transmission can determine the received signal strength (RSSI) and the value of this RSSI can be expected to be higher when the sender and receiver are close to each other than when they are not. In the system developed, the sensors in effect are simply the wireless receivers. These receivers calculate the sensed signal strength at any given point of time and report it to the base station. As the signal strength reported by motes closer to the sender would be higher than those aren't, that serves as a hint for the zone in which the sender is present.

An often overlooked aspect when designing a GPS-based warning system is the quality of wireless communication and the effective distance range at which the data containing these GPS locations of nearby vehicles can be exchanged inside a surface mine. The topology of a surface mine is different than that of regular roads and contains deep pits, high obstacles, and sloped muddy roads, which cause a hidden line of sight for the wireless radios being used leading to poor reception. At the same time, some other conditions are more relaxed when compared with regular roads: (i) the number of vehicles per unit area is much lower thereby reducing channel contention, and (ii) the chances of interference from other devices 
such as Wi-Fi routers and Bluetooth devices are also lower. In this work, the packet reception characteristics and the received radio signal strength at different source-destination distances for IEEE $802.11 \mathrm{a}, \mathrm{b}$, and p radios were investigated inside an actual surface mine. It was observed that by characterizing effective communication range for 802.11 radios in such surroundings, one can determine the effectiveness of such collision warning systems for operation in surface mines and identify the appropriate 802.11 radio type to use. IEEE 802.11p is supposed to support low-latency communication among vehicles. However, in the use case considered here(or other private areas), which is surface mines, there's not much of interference from other transmissions, a specialized standard as $802.11 \mathrm{p}$ is not a strict requirement. 


\section{Chapter 3}

\section{Proximity detection in surface mines}

In this chapter, an overview of the proximity detection system is provided. Describing the problem addressed by this system, experimental setup, conduction of initial experiment and final deployment of the system and the results obtained are the goals of this chapter.

\subsection{Problem}

This section explains the motivation for the development of a proximity detection system. In surface mine areas, the operator of a huge truck cannot easily sense entities (human/vehicle) moving or stationary around the trucks' location. This problem is aggravated by the cases in which these entities occur in the blind spots of the truck or entirely at the back of it. The idea pursued here is that if every such movable entity that could occur in the area can be equipped with suitable sensors which serve as markers for both the truck and the mobile entity, their presence can be detected by an operator in the truck provided with a suitable interface. The system developed here is such that the location of the entity can be determined precisely as being one of the 8 zones around the truck.

\subsection{Setup}

This section describes the system setup used to design this proximity detection system. Both the heavy-truck and the approaching entity (human/vehicle) were marked adequately 


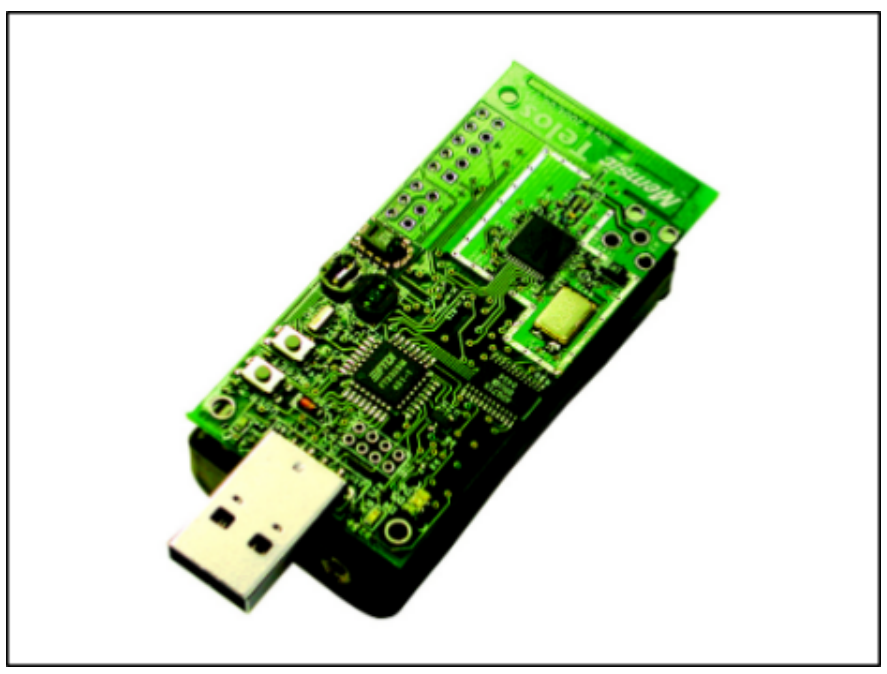

Figure 3.1: TelosB mote

to aid detection.

The primary components of this system are TelosB motes with CC2420 radios embedded. With their miniature size, wireless transmission capability and easy programmability, TelosB motes make good candidates for being used as sensors.

Four TelosB motes were attached around a huge Caterpillar truck, thereby dividing the space around it into 8 zones - 4 being directly opposite to each mote and 4 other being in the corners occurring between every two motes. We refer to these 4 motes as detectors as they exist to detect the presence of transmission from other approaching markers (read motes).

Any entity that needs to be detected carries a sender TelosB mote. The transmissions from this sender mote are sensed by the four detector motes which then calculate the parameter - Received Signal Strength Indicator(RSSI). The detectors introduce this RSSI information in to the packets and rebroadcast it expecting the base station to pick them up. By design, the base station ignores the original packets from the sender mote and hence only considers the transmissions from the detector motes.

One TelosB mote was put inside the vehicle to act as base station, receiving and further processing the transmissions from the 4 detector motes. The base station was connected to a laptop powered by Ubuntu 12.04 Desktop Edition with TinyOS runtime environment installed. A program listens to the USB interface to receive the data being streamed by the 


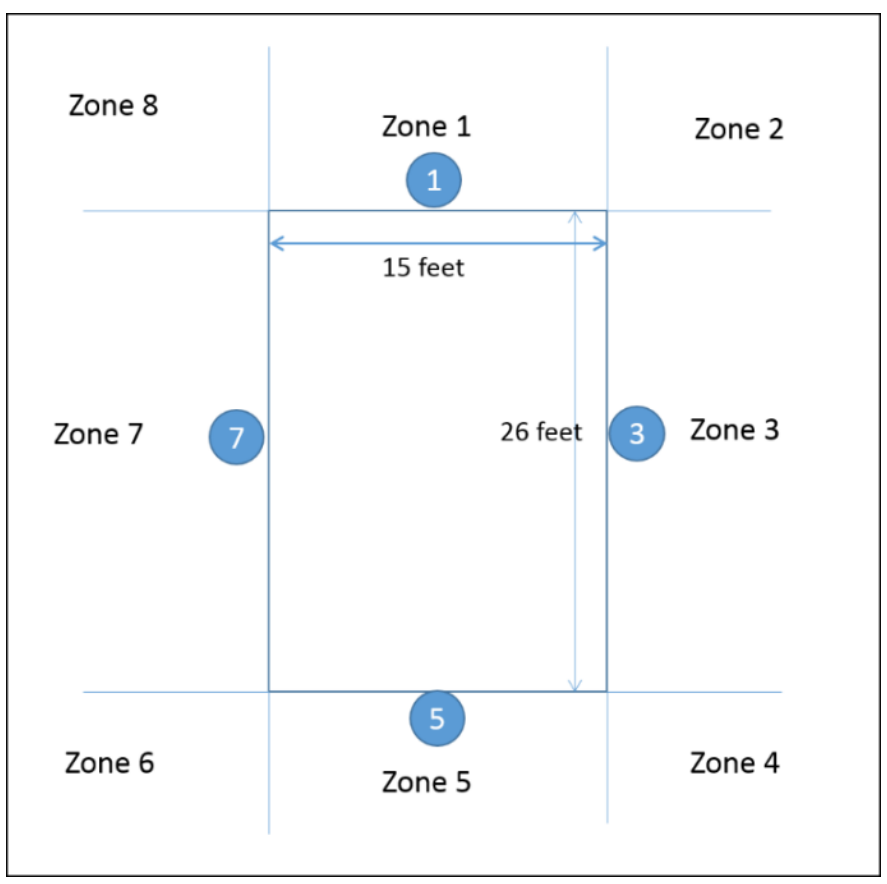

Figure 3.2: Schematic division of zones around a truck

base station. At the end of every second, the program averages the RSSI values calculated for packets from each mote and determines the zone to which the detected entity is close to. The resulting information is displayed on the screen on a user-friendly interface with the truck and the entity represented by appropriate markers on a graphical map of the mine.

All motes were programmed using TinyOS operating system for wireless sensor networks.

\subsection{Initial testing and final deployment}

Every transmission in this network is a broadcast and every packet transmitted contains the ID of its sender. It is the duty of the receiver to selectively process a heard packet. A person carrying the sender mote was made to stand in each zone for 30 seconds. The mote transmits a packet with its ID and an empty field that should be filled with RSSI later by detector motes. The detector motes calculate the RSSI on receipt, include it in the packet and forward it to the base station.

The program running on the computer with base station records all the packets received for a second. At the end of every second, the RSSI values from each detector are averaged 


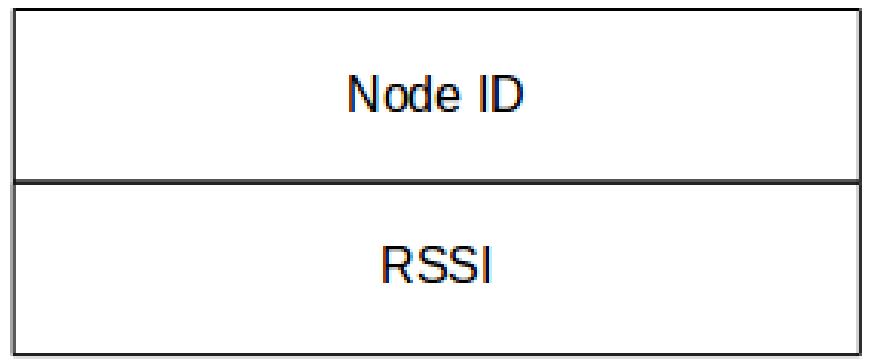

Figure 3.3: Structure of the packet used in the proximity detection sytem

out to arrive at a single mean RSSI value per detector. The highest and second highest means of RSSI values and the IDs of the motes that gave them out are recorded.

In the final deployment of the system, the program was modified to calculate the difference of highest and second highest mean RSSI values at the end of every second. Based on the region of experimentally determined values the difference falls in, the sender is said to be either close to mote $X$ or between mote $X$ and mote $Y$.

\subsection{Results}

When the sender is in the zones $1,3,5$ and 7 , which means closer to a single mote than the rest, the difference between highest RSSI and the second highest RSSI is huge.

On the other hand, if it is in the zones 2,4,6 and 8, which means not any close to any mote but between two of them, signal from none is stronger than the other and hence the difference between highest RSSI and the second highest RSSI is not huge.

During the test in mines, the sender was broadcasting packets at the rate of 5 per second and the detectors would immediately forward it to the base station with almost no delay. This test was conducted to cover all the 8 zones at 4 different distances from the setup - 3m, $6 \mathrm{~m}, 9 \mathrm{~m}$, and $12 \mathrm{~m}$. The difference in the highest and second highest RSSI values (in $\mathrm{dBm}$ ) is plotted over the distances in the following graph:

We observe that the thresholds can be set to $15 \mathrm{dBm}$ for 'closeness' and $7 \mathrm{dBm}$, to declare 'betweenness'. A difference in the highest and second highest RSSI above or equal to $15 \mathrm{dBm}$ can be taken to be the case where the sender is close to mote $X$ and when it is 


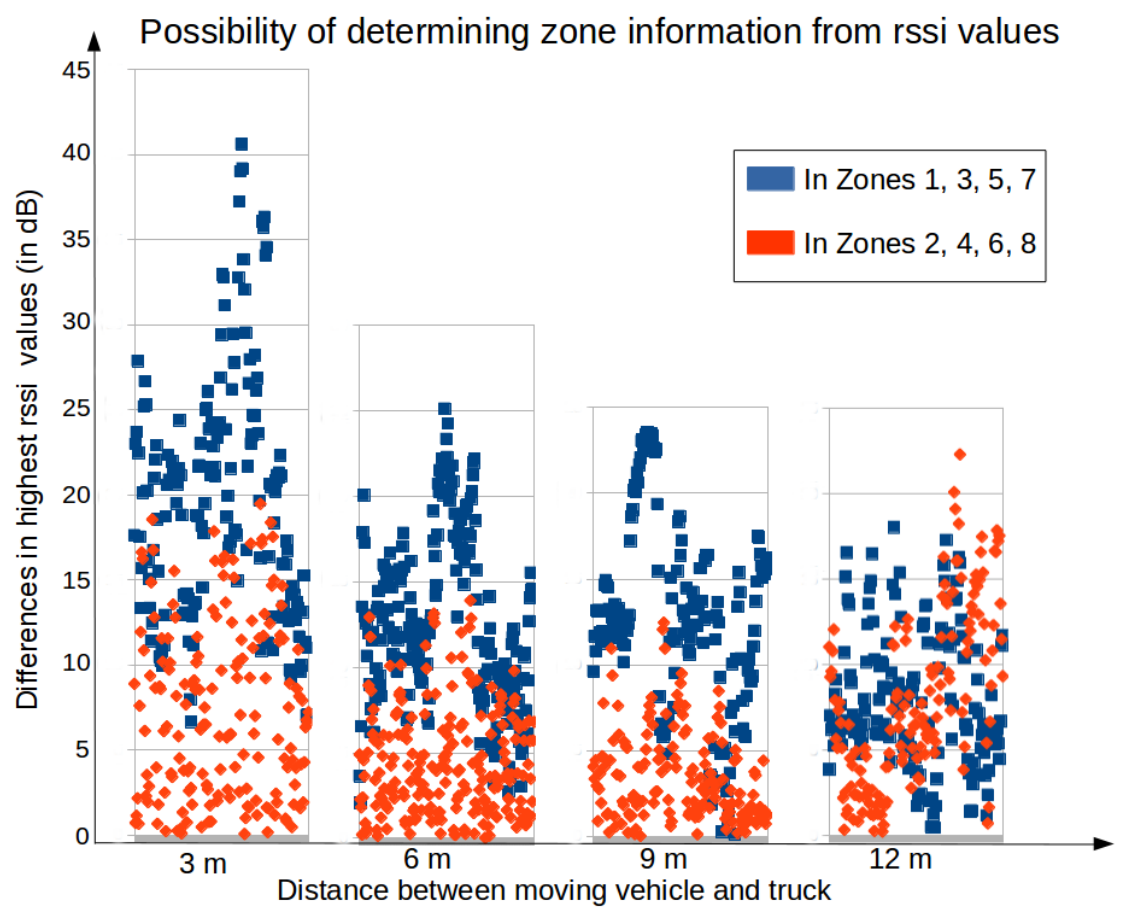

Figure 3.4: Possibility of determining zone information for various distances between sender and truck

below or equal to $7 \mathrm{dBm}$, the sender can be said to be in the region occurring between the motes $X$ and $Y$. Beyond 10m, this system doesn't precisely determine the zone.

In the Figure 3.4, correct zoning refers to the situation where the the sender was known to be in zone $\mathrm{X}$ and the system reported the position to be zone $\mathrm{X}$ too.

Neighbour zoning refers to the situation where the sender was known to be in zone $\mathrm{X}$ but the system reported the position to be in the zone next to it or the one before.

From the plots it can be seen that this proximity detection system gives correct zone information above $80 \%$ of the time and only a preceding or succeeding zone, otherwise. This may be improved further by adjusting the transmission power levels of the motes involved.

The results and the accuracy values reported here can vary with the frequency of transmissions, wireless transmission power levels of the TelosB motes and vehicles of different dimensions than the one used in this experiment. 


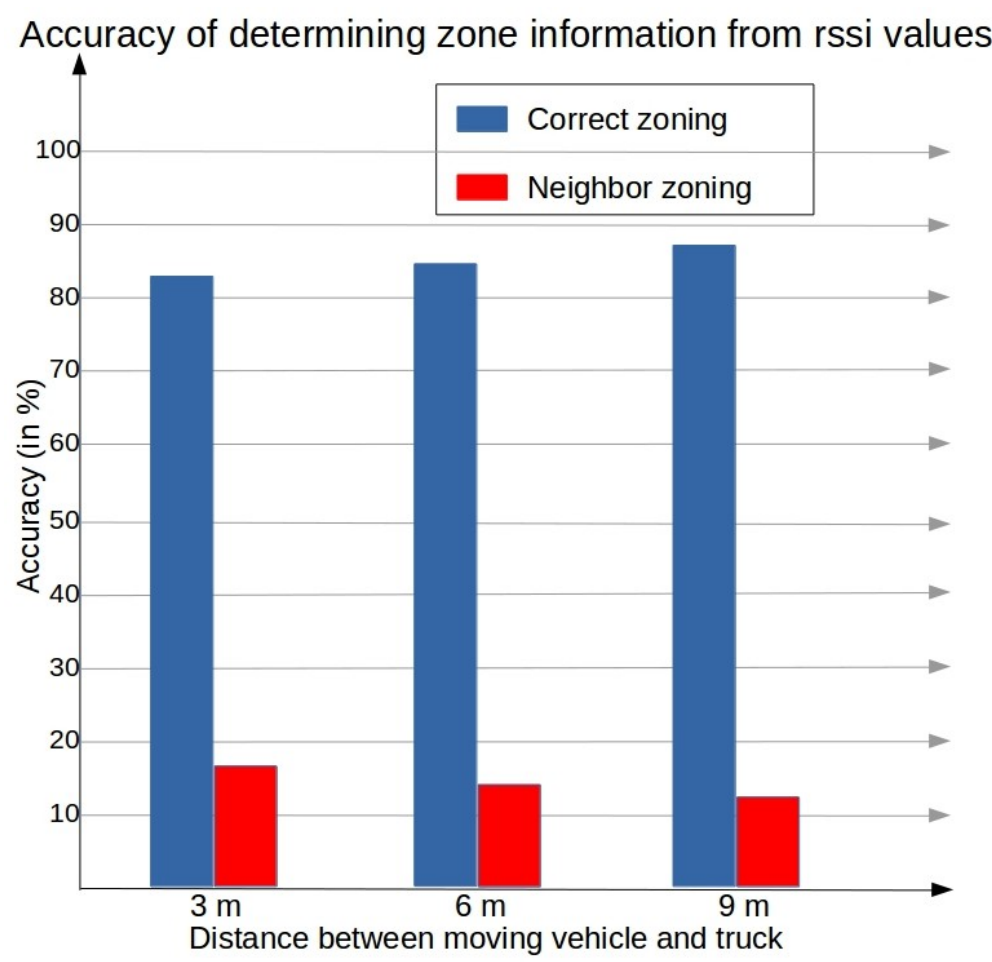

Figure 3.5: Accuracy of the proximity detection system tested at distances - 3m, $6 \mathrm{~m}$ and $9 \mathrm{~m}$ 


\section{Chapter 4}

\section{The wireless standards evaluation in surface mines}

This chapter discusses the task of evaluating wireless transmission standards in surface mines. We start off by bringing up the problem statement considered, the setup and approach taken for this task of evaluation and conclude with the results obtained.

\subsection{Problem}

GPS-based proximity warning systems are increasingly being recommended for collision avoidance and vehicular safety, in the context of regular personal vehicles as well as heavy mining trucks. GPS devices can provide location estimates with an accuracy of $3-4 \mathrm{~m}$ (about 10 feet). Therefore, GPS devices along with some form of wireless communication are increasingly being used for detecting approaching vehicles and for collision avoidance[29] [30][32][31][33]. In this work, we used a GPS-based system for collision detection from larger distances (¿10m). At very close distances, the GPS systems are not accurate enough to correctly estimate the direction in which a nearby obstacle has been detected, although they can estimate that there is an object nearby. Therefore, for closer distances, we have used an RF-based system. Secondly, as noted earlier, some form of wireless communication is needed so that GPS locations of nearby vehicles and objects can be communicated to other approaching vehicles. We evaluated three Wi-Fi based standards in an actual surface mine 

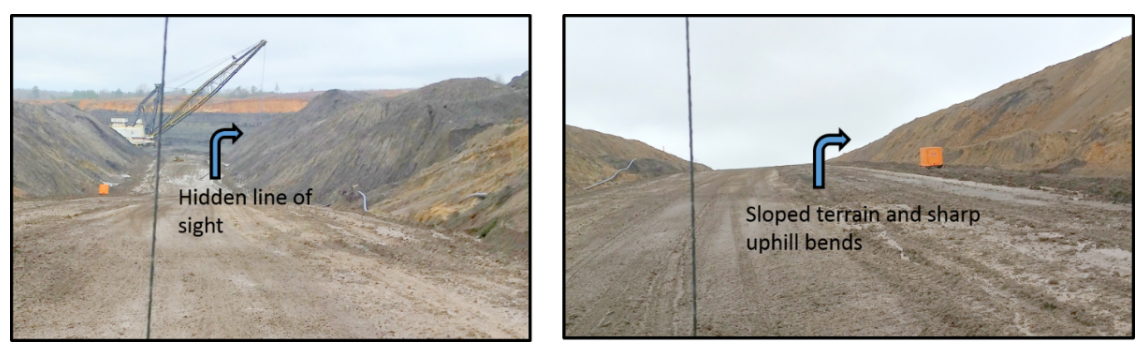

Figure 4.1: (On left) mud pile causing hidden line of sight. (On right) sloped terrain.

setting to understand their effectiveness in communicating the locations from a sufficient distance such that there is enough time for drivers to react. The basic idea in these systems is to use a GPS receiver along with some form of wireless communication module on each vehicle to provide updates about its location to other vehicles. These updates can be provided in two ways: (i) a centralized cellular or long-range communication infrastructure can be used to communicate data from each vehicle to a processing center and then re-broadcast data from there to all the vehicles. (ii) GPS data can be communicated in a decentralized peer-to-peer manner only to vehicles that are nearby. The former approach is more cumbersome and expensive: it involves excessive setup costs inside surface mines as well as high cost for data usage. Therefore, we used the latter mechanism by utilizing IEEE 802.11 (Wi-Fi) radios in an ad-hoc mode. In this mode, two Wi-Fi radios can communicate with each other as soon as they come within communication range of each other.

The Wi-Fi Alliance defines Wi-Fi as a wireless local area network (WLAN) product based on the IEEE 802.11 standards. IEEE 802.11 is a set of media access control (MAC) and physical layer (PHY) specifications for implementing wireless computer communication in the 2.4, 5, and $60 \mathrm{GHz}$ frequency bands. The IEEE 802.11 family consists of a series of standards that use different modulation techniques and frequency bands, but use the same underlying communication protocol. Here, we specifically considered the IEEE 802.11 a, b, and $\mathrm{p}$ series for evaluation.

The 802.11a specification is an amendment to the IEEE 802.11 family that uses the same frame format and link layer protocol as the original 802.11 specification, but operates in the $5.8 \mathrm{GHz}$ band and uses the orthogonal frequency division multiplexing (OFDM) technique 
for signal modulation. The advantage of 802.11a is the use of the $5 \mathrm{GHz}$ frequency instead of the crowded 2.4 GHz ISM band, where interference from other devices often can be found.

IEEE 802.11b is an amendment of IEEE 802.11 that uses the direct-sequence spread spectrum (DSSS) with data rates of 5.5 and $11 \mathrm{Mbps}$ in the $2.4 \mathrm{GHz}$ range. One disadvantage is the use of the $2.4 \mathrm{GHz}$ frequency where many other devices operate, such as Bluetooth devices and Wi-Fi routers that may cause wireless channel interference. However, in mining environments, we do not expect this interference.

The 802.11p supports wireless access in vehicular environments (WAVE) and contains enhancements required to support Intelligent Transportation Systems applications[37]. The standard uses the 5.9 GHz ISM band and enables car-to-car or vehicle-to-vehicle communication. Similar to IEEE 802.11a, 802.11p radio is based on matured orthogonal frequencydivision multiplexing (OFDM) technology. The medium access control (MAC) layer functionality is slightly modified to include provision for rapid communication of DSRC devices with no need for authentication or authorization processes as in the original 802.11 standard.

An often overlooked aspect when designing a GPS-based warning system is the quality of wireless communication and the effective distance range at which GPS locations of nearby vehicles can be received inside a surface mine. The topology of a surface mine is different than that of regular roads and contains deep pits, high obstacles, and sloped muddy roads, which cause a hidden line of sight for the wireless radios being used leading to poor reception. At the same time, some other conditions are more relaxed when compared with regular roads: (i) the number of vehicles per unit area is much lower thereby reducing channel contention, and (ii) the chances of interference from other devices such as Wi-Fi routers and Bluetooth devices are also lower. In our work, we systematically investigated the packet reception characteristics and the received radio signal strength at different source-destination distances for IEEE $802.11 \mathrm{a}, \mathrm{b}$, and p radios, inside an actual surface mine. By characterizing effective communication range for 802.11 radios in these surroundings, we are able to determine the effectiveness of such collision warning systems for operation in surface mines and identify 


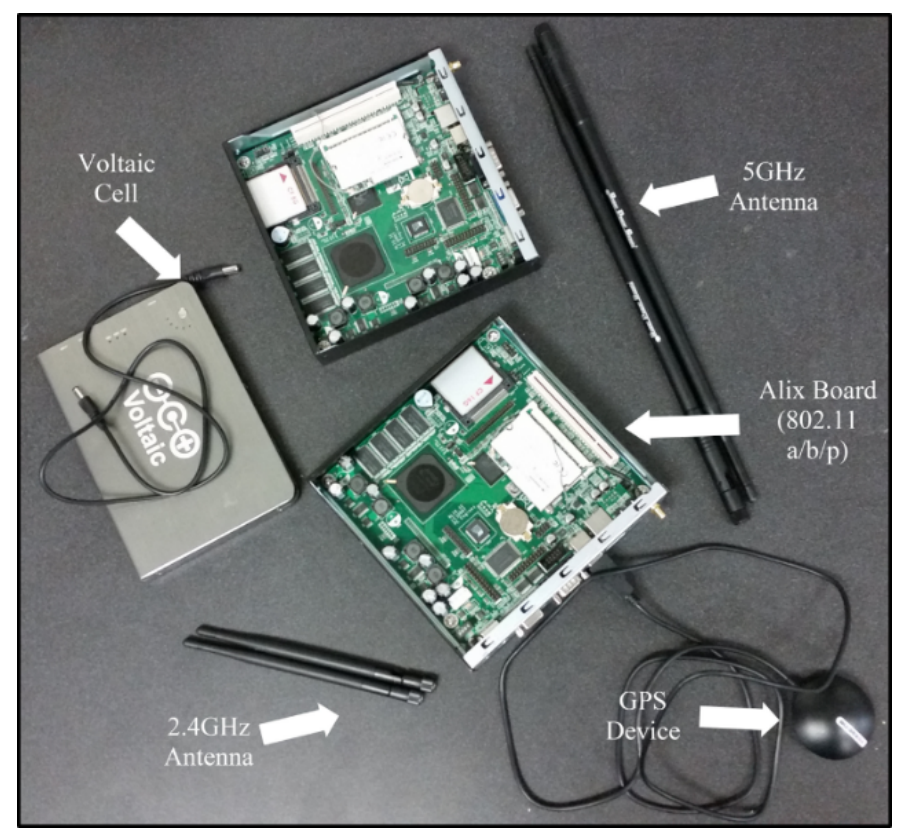

Figure 4.2: Components used for wireless standards evaluation in surface mines

the appropriate 802.11 radio type to use. We first describe our system setup, the procedure followed for the tests and then present the results of our evaluation.

\subsection{Setup}

Two Alix (Type-1E) boards with CM9-GP network cards and 9dBi dual band $2.4 \mathrm{GHz}$ / $5 \mathrm{GHz}$ antennas were used for testing the quality of wireless transmissions. For all the wireless standards evaluated, the bitrate was fixed at $6 \mathrm{Mbps}$ and the transmit power was chosen to be $23 \mathrm{dBm}$. Ubuntu 12.04 Server Edition was used as the operating system to run requisite programs on these single board computers.

The boards were programmed to establish an ad-hoc network between them, whenever they come close to each other in different wireless standards during different parts of the experiment.

One board designated as the 'sender' runs a custom developed program that broadcasts its current GPS coordinates at the rate of 5 per second. A Globalsat BU-353 GPS receiver was used to obtain GPS coordinates. Another board, designated as 'receiver', used a packetcapturing program 'Wireshark' that logged every packet received. The log contained the 
details - timestamp, signal strength and data contained in each packet.

\subsection{Procedure}

The 'receiver' board was stay put at a fixed location which runs a packet reception program Wireshark to log each packet transmitted with necessary fields - 'received time', 'Received Signal Strength Indicator(RSSI)' and 'packet id' along with location information, etc.

A person holding the 'sender' board was made to walk along a fixed straight-line path for a maximum distance of $900 \mathrm{ft} .(274.32 \mathrm{~m}$ approx). This sender halts at every $15 \mathrm{ft}$. (4.572m approx.) for 30 seconds to collect adequate amount of points in the logs of radio transmissions. The sending rate was fixed at $5 \mathrm{~Hz}$ for this experiment.

The packet rate is determined as:

$$
\frac{\text { No. of packets logged at given distance }}{\text { No. of packets transmitted in that time frame }}
$$

At each distance, the median of the obtained RSSI values is chosen as the representative value. The values are plotted over the distances for all the wireless standards and their pattern is compared.

Also, at each distance, the median of the observed packet reception rate is chosen as the representative value. The values are plotted over the distances for all the wireless standards and their pattern is compared.

For all the wireless standards evaluated in the tests, the bitrate was fixed at $6 \mathrm{Mbps}$ and the transmit power was $23 \mathrm{dBm}$. 
Tests have been conducted while both the sender and receiver are in:

1. $802.11 \mathrm{a}$

2. $802.11 b$

3. $802.11 \mathrm{p}$

All these tests were conducted in 4 different locations that are typical of a surface mine:

\begin{tabular}{||c|l||}
\hline \multicolumn{1}{||c|}{ Case } & Description \\
\hline Direct Line of sight & Sender moves on a straight line \\
& Receiver remains at the starting point \\
\hline Hidden line of sight & $\begin{array}{l}\text { Sender moves on a straight line } \\
\text { Receiver hides behind a mud pile normal to the } \\
\text { starting point }\end{array}$ \\
\hline Receiver at the top of incline & $\begin{array}{l}\text { Receiver stays at the top of an inclined surface } \\
\text { Sender moves down the incline }\end{array}$ \\
\hline Receiver at the bottom of incline & $\begin{array}{l}\text { Receiver stays at the bottom } \\
\text { Sender moves up the inclined surface }\end{array}$ \\
\hline
\end{tabular}

Table 4.1: 4 locations where wireless standards evaluation was conducted 


\subsection{Results}

The data collected in 4 different locations was used to obtain comparative graphs of median packet reception rates and median RSSI values over 3 different wireless standards.

\section{Direct line of sight}

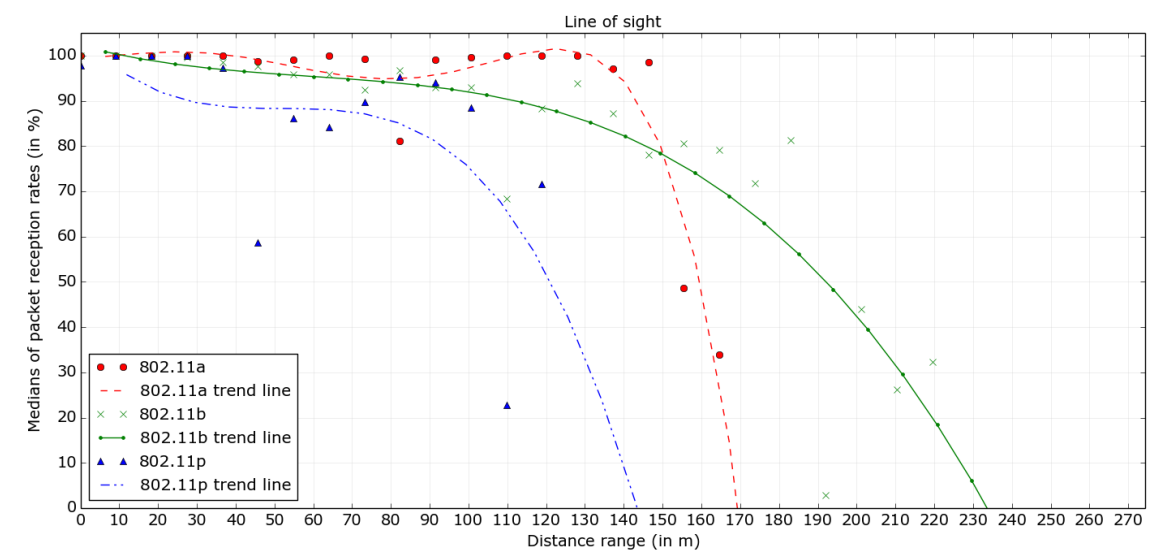

Figure 4.3: Median packet reception rate as a function of sender-receiver distance (direct line of sight)

From the trend-lines plotted over the medians of packet rates, 802.11b seems to perform well for larger distances $(>170 \mathrm{~m})$. At any distance, its performance is well above that of 802.11p. 802.11a too was as good as 802.11b for shorter distances $(<170 \mathrm{~m})$.

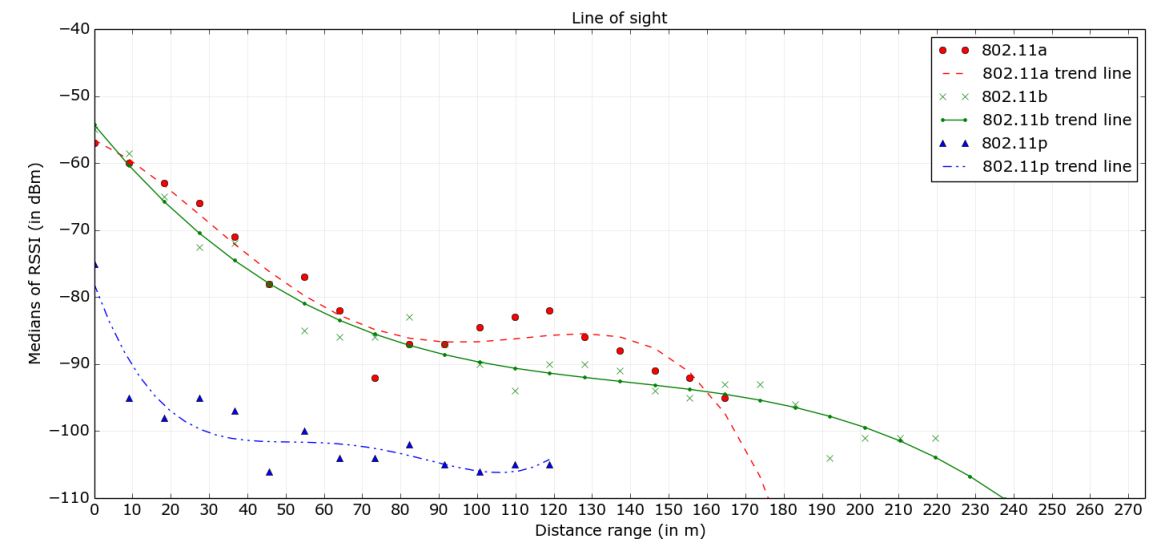

Figure 4.4: RSSI trend as a function of sender-receiver distance (direct line of sight)

The medians of RSSI values observed at each distance for all the three wireless standards is as above. 


\section{Hidden line of sight}

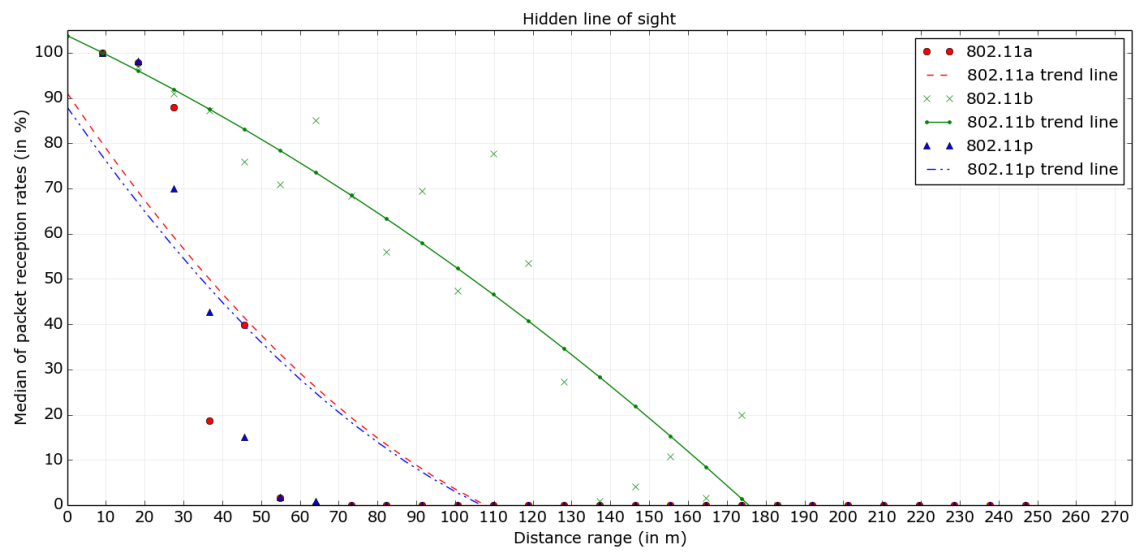

Figure 4.5: Median packet reception rate as a function of sender-receiver distance (hidden line of sight)

From the trend-lines plotted over the medians of packet rates, it can be seen that $802.11 \mathrm{~b}$ clearly performs well for any given distance. Both 802.11a and 802.11p couldn't do well due to their shorter wavelengths not able to overcome obstacles when compared to $802.11 \mathrm{~b}$

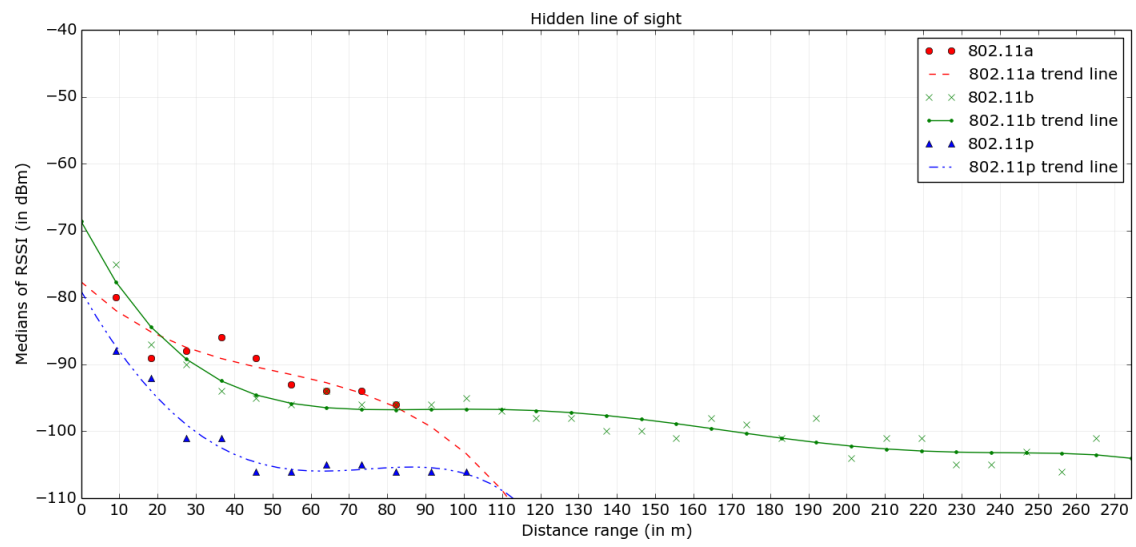

Figure 4.6: RSSI trend as a function of sender-receiver distance (hidden line of sight)

The medians of RSSI values observed at each distance for all the three wireless standards is as above. 


\section{Receiver at the top of incline}

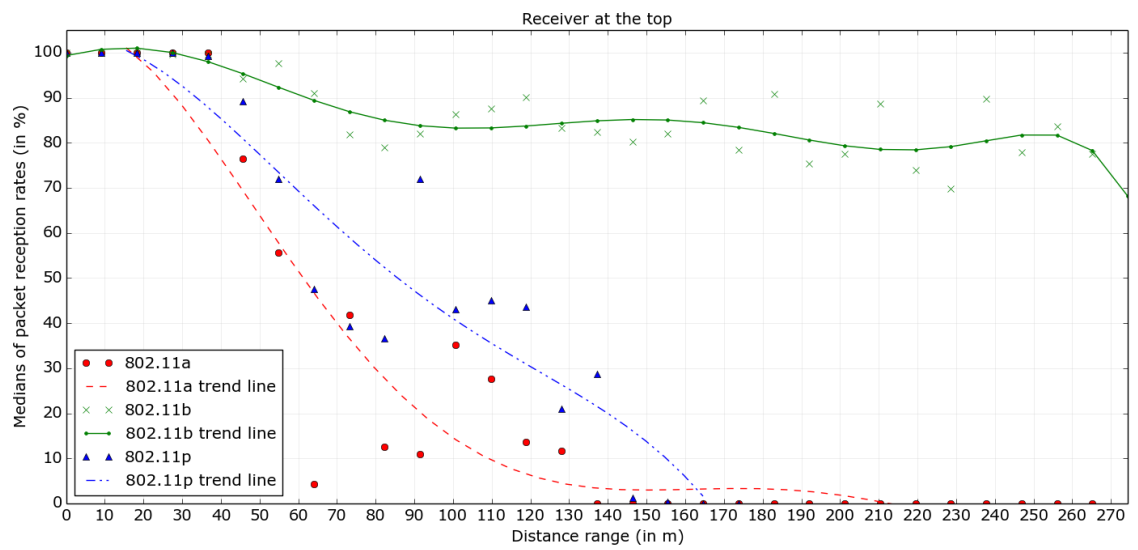

Figure 4.7: Median packet reception rate as a function of sender-receiver distance (receiver at the top of incline)

From the trend-lines plotted over the medians of packet rates, it can be said that $802.11 \mathrm{~b}$ clearly performs well for any given distance. The trends in 802.11a are even lower than that of $802.11 \mathrm{p}$.

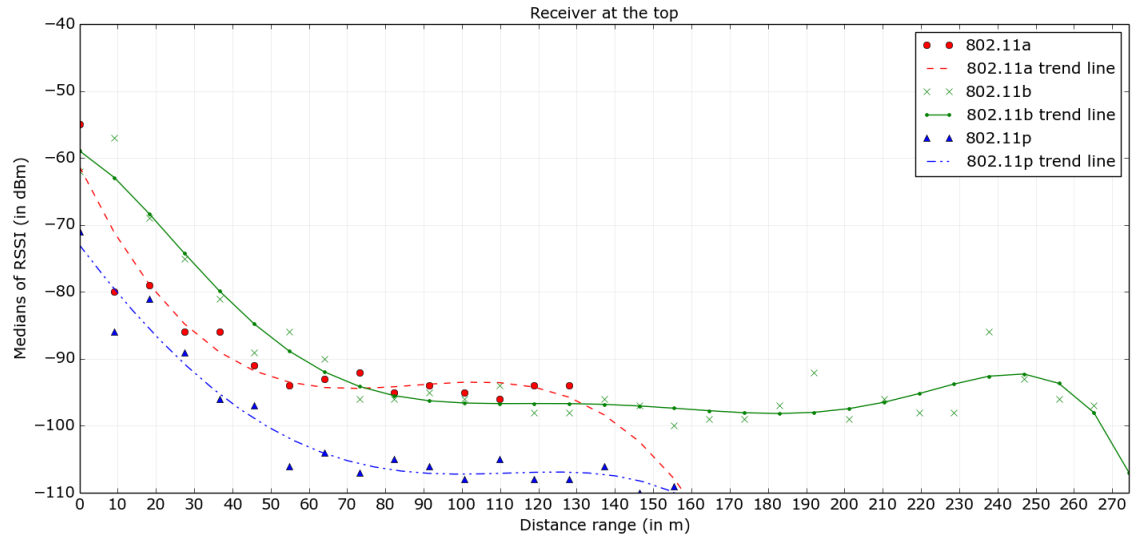

Figure 4.8: RSSI trend as a function of sender-receiver distance (receiver at the top of incline)

The medians of RSSI values observed at each distance for all the three wireless standards is as above. 


\section{Receiver at the bottom of incline}

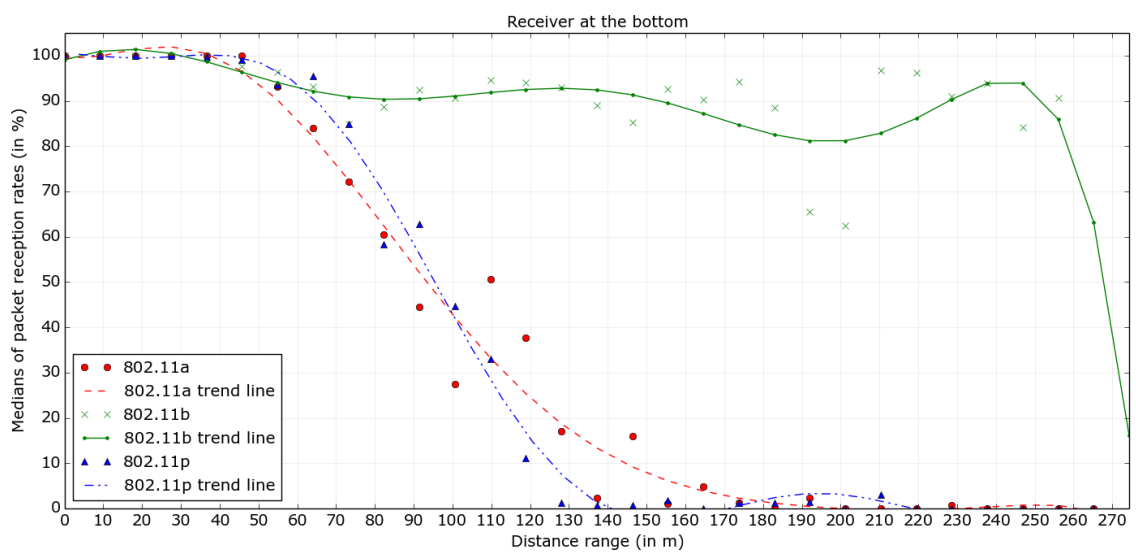

Figure 4.9: Median packet reception rate as a function of sender-receiver distance (receiver at the bottom of incline)

From the above, it is evident that $802.11 \mathrm{~b}$ is a clear winner for any distance. The trends in 802.11p and 802.11p are almost the same and are lower than that of $802.11 \mathrm{~b}$

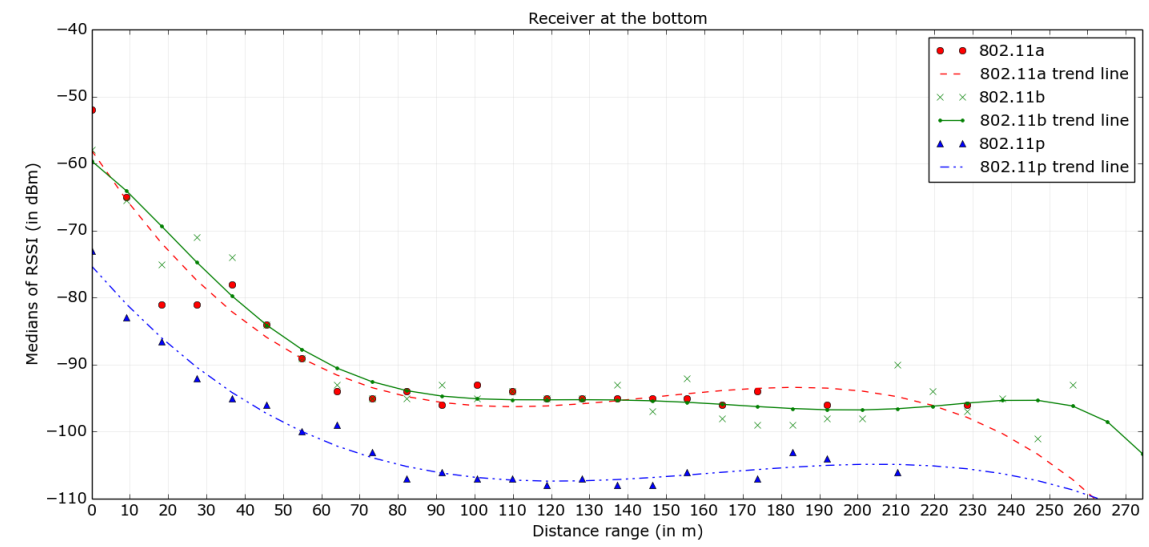

Figure 4.10: RSSI trend as a function of sender-receiver distance (receiver at the bottom of incline)

The medians of RSSI values observed at each distance for all the three wireless standards is as above. 
In the table below, we list the approximate reception range at which more than $75 \%$ of the packets are received on average for each of the scenarios. We observe that with IEEE 802.11b, even in the worse condition (hidden line of sight), packets can be received at a distance of $60 \mathrm{~m}$ (200 feet) from each other, providing adequate reaction time for the drivers. (At a speed of $32 \mathrm{kmph}$ (20mph), this gives drivers about 9 seconds of reaction time.)

\begin{tabular}{|c||c||c||c|}
\hline \multicolumn{1}{|c||}{} & $802.11 \mathrm{~b}$ & $802.11 \mathrm{a}$ & $802.11 \mathrm{p}$ \\
\hline Direct line of sight & $152 \mathrm{~m}$ (500 feet) & $152 \mathrm{~m}$ (500 feet) & $98 \mathrm{~m}$ (320 feet) \\
\hline Hidden line of sight & $60 \mathrm{~m}$ (200 feet) & $12 \mathrm{~m}$ (40 feet) & $12 \mathrm{~m}$ (40 feet) \\
\hline Receiver at top & $183 \mathrm{~m}$ (600 feet) & $45 \mathrm{~m}$ (150 feet) & $55 \mathrm{~m}$ (180 feet) \\
\hline Receiver at bottom & $183 \mathrm{~m}$ (600 feet) & $70 \mathrm{~m}$ (230 feet) & $80 \mathrm{~m}$ (260 feet) \\
\hline
\end{tabular}

Table 4.2: Average distance at which more than $75 \%$ packets are received under different topological conditions in surface mines for each of the three radios 


\section{Chapter 5}

\section{Conclusion and Future work}

Conclusions drawn from the experiments conducted in this work are presented here. Possible extensions of this work are proposed at the end.

\subsection{Conclusion}

In this work, we described the use of wireless communication technology aimed at addressing concerns of timely proximity warning and collision avoidance in surface mines. We first described an IEEE 802.15.4 radio-based system for proximity zoning of tagged objects at distances of less than $10 \mathrm{~m}$. The design and development of low-cost and cost-effective, easily-configurable and deployable proximity detection system that can be used for improving safety in regions such as surface mines was explained. This system reports the zone in which a foreign entity is located with respect to the position of vehicle. Our system is shown to be able to reliably classify nearby objects into one of 8 zones surrounding a CAT 769 truck. The 802.15.4 radio-based proximity zoning system can thus adequately complement Wi-Fi-GPS based systems that are better suited for collision avoidance at distances greater than $10 \mathrm{~m}$ away from a vehicle.

We then characterized the performance of a family of IEEE 802.11 standards inside an actual surface coal mine for communicating GPS data to nearby vehicles. We observed that the IEEE $802.11 \mathrm{~b}$ standard operating in the $2.4 \mathrm{GHz}$ range outperforms $802.11 \mathrm{p}$ and $802.11 \mathrm{a}$ standards, in terms of the effective distance at which GPS data can be reliably received. 
The tests were conducted in different topologies - Direct line of sight, Hidden line of sight, Receiver at the top of incline and Receiver at the bottom of incline. Despite the fact that 802.11p is being touted as the standard for vehicular communication networks, for this case of quick exchange of short bursts of data for the purposes of proximity detection, the already popular 802.11b standard performs well with less packet loss for longer distances.

\section{$5.2 \quad$ Future work}

The applications of wireless sensor networks open up multiple possibilities in topics such as safety, etc. in hazardous areas like surface mines with huge moving equipment. This work examined the applicability of miniature wirelessly transmitting devices as 'proximity sensors'. The system was demonstrated for one-vehicle and one-approacher situation. More studies are required before wide-scale deployment to verify and enhance the interaction among multiple entities moving randomly among multiple vehicles.

The wireless standards quality evaluation tests can be conducted in more areas such as deep pits and around mud-piles high enough to be approximated as mountains and such. It would be interesting to check for any multiple receptions due to echoes and how it affects the quality of transmissions - also known as multipath propagation.

The wireless transmissions test was conducted at default power levels of each of the standards described by the vendor. The values shown here might change with a change in power level. We expect the results to vary proportionately but real tests are suggested to confirm the validity of this claim.

Not much channel contention was present during these tests as they involved just two vehicles - single transmitter and single receiver. Presence of seven or more vehicles transmitting simultaneously might make the channels busy which might lead to increase in packet loss even for 802.11b. More tests simulating the real conditions are warranted before adoption of this system. 


\section{References}

[1] Enji Sun, Antonio Nieto, Zhongxue Li, and Vladislav Kecojevic, "An integrated information technology assisted driving system to improve mine trucks-related safety," Safety science, vol. 48, no. 10, pp. 1490-1497, 2010.

[2] Meng Zhang and Vladislav Kecojevic, "Intervention strategies to eliminate truck-related fatalities in surface coal mining in west virginia," International journal of injury control and safety promotion, , no. ahead-of-print, pp. 1-15, 2015.

[3] PUB SC of IEEE 802.11, "Ieee 802.11 presentations — what 802.11 is doing," 2015.

[4] Wikipedia, "Ieee 802.11 standards and amendments - Wikipedia, the free encyclopedia," 2015, [Online; accessed 2015-09-03].

[5] Wikipedia, "Ieee 802.11a-1999 — Wikipedia, the free encyclopedia," 2015, [Online; accessed 2015-09-03].

[6] Venkataraghavasivanagashashank Sabniveesu, Ajay Kavuri, Rahul Kavi, Vinod Kulathumani, Vladislav Kecojevic, and Ashish Nimbarte, "Use of wireless, ad-hoc networks for proximity warning and collision avoidance in surface mines," International Journal of Mining, Reclamation and Environment, vol. 29, no. 5, pp. 331-346, 2015.

[7] Joseph Polastre, Robert Szewczyk, and David Culler, "Telos: enabling ultra-low power wireless research," in Information Processing in Sensor Networks, 2005. IPSN 2005. Fourth International Symposium on. IEEE, 2005, pp. 364-369.

[8] LevI. Dorman, "Automated local evaluation in real time (alert)," in Encyclopedia of Natural Hazards, PeterT. Bobrowsky, Ed., Encyclopedia of Earth Sciences Series, pp. 31-31. Springer Netherlands, 2013.

[9] Automated Local Evaluation in Real Time Users Group, "http://www.alertsystems.org," [Online; accessed 2015-10-30].

[10] Ning Xu, "A survey of sensor network applications," IEEE Communications Magazine, vol. 40, no. 8, pp. 102-114, 2002.

[11] Alan Mainwaring, David Culler, Joseph Polastre, Robert Szewczyk, and John Anderson, "Wireless sensor networks for habitat monitoring," in Proceedings of the 1st ACM international workshop on Wireless sensor networks and applications. ACM, 2002, pp. 88-97. 
[12] Public Affairs Office of the UC Berkeley College of Engineering, "http://www.coe.berkeley.edu/labnotes/0701brainybuildings.html," 2001, [Online; accessed 2015-10-30].

[13] TinyOS Working Group, "Tinyos documentation wiki," 2015, [Online; accessed 201509-03].

[14] K. Chintalapudi, T. Fu, Jeongyeup Paek, N. Kothari, S. Rangwala, J. Caffrey, R. Govindan, E. Johnson, and S. Masri, "Monitoring civil structures with a wireless sensor network," Internet Computing, IEEE, vol. 10, no. 2, pp. 26-34, March 2006.

[15] Xiaoguang Niu, Xi Huang, Ze Zhao, Yuhe Zhang, Changcheng Huang, and Li Cui, "The design and evaluation of a wireless sensor network for mine safety monitoring," in Global Telecommunications Conference, 200\%. GLOBECOM '0\%. IEEE, Nov 2007, pp. 1291-1295.

[16] D. Djenouri, "Preventing vehicle crashes through a wireless vehicular sensor network," in Communications, 2008 24th Biennial Symposium on, June 2008, pp. 320-323.

[17] T.I. King, W.J. Barnes, H.H. Refai, and J.E. Fagan, "A wireless sensor network architecture for highway intersection collision prevention," in Intelligent Transportation Systems Conference, 200\%. ITSC 200\%. IEEE, Sept 2007, pp. 178-183.

[18] T.M. Ruff, "Overview of proximity warning technology and approaches.," 2010.

[19] Office of Mine Safety and Health Research (OMSHR), "Engineering considerations and selection criteria for proximity warning systems for mining operations," .

[20] T.M. Ruff, "Advances in proximity detection technologies for surface mining equipment," .

[21] M.A. Reyes, "Status of the international implementation of proximity warning systems.," 2010.

[22] T Ruff and J Steele, "Recent advances in proximity warning technology for surface mining equipment," Mining Engineering, vol. 56, no. 12, pp. 68-72, 2004.

[23] Sensors Job Board, "Choosing an ultrasonic sensor for proximity or distance measurement part 1 - acoustic considerations," .

[24] Todd Ruff, "Evaluation of a radar-based proximity warning system for off-highway dump trucks," Accident Analysis 83 Prevention, vol. 38, no. 1, pp. 92-98, 2006.

[25] Nicky Guenther, Nicky Guenther David Duncan Paul Harrison, and Andre de Kock, "The application of laser sensing technology to proximity detection in the mining industry," .

[26] Simon Walker, "Proximity detection aids minesite awareness," Engineering and Mining Journal, vol. 215, no. 11, pp. 34, 2014. 
[27] Acumine, "Collision avoidance safety system (acass)," 2010.

[28] Eric Marks and Jochen Teizer, "Proximity sensing and warning technology for heavy construction equipment operation," in Construction Research Congress, West Lafayette, Indiana, 2012, pp. 981-990.

[29] William H Schiffbauer, "Active proximity warning system for surface and underground mining applications," Mining engineering, vol. 54, no. 12, pp. 40-48, 2002.

[30] Tristan Cooke and Tim Horberry, "Driver satisfaction with a modified proximity detection system in mine haul trucks following an accident investigation," in Ergonomics Australia. Human Factors and Ergonomics Society of Australia, 2011, vol. 2011, pp. $1-6$.

[31] A Nieto, S Miller, and R Miller, "Gps proximity warning system for at-rest large mobile equipment," International Journal of Surface Mining, Reclamation and Environment, vol. 19, no. 1, pp. 75-84, 2005.

[32] T.M. Ruff and T.P. Holden, "Mine eyes," 2002.

[33] D Schmidt, "Safemine team up for collision avoidance system. coal age," 2014.

[34] r.h.lee, "Dsss? cck? dqpsk? help! — certforums," 2015, [Online; accessed 2015-09-03].

[35] Jacqueline Kim Anthony Bruno, CCDA Exam Certification Guide CCDASelf Study, 640 - 861 2nd Edition, Cisco Press, 2003.

[36] Dr. Michele Weigle, "Standards wave/dsrc/802.11p," 2008, [Online; accessed 2015-09$03]$.

[37] Ching-Ling Huang, Yaser P Fallah, Raja Sengupta, and Hariharan Krishnan, "Adaptive intervehicle communication control for cooperative safety systems," Network, IEEE, vol. 24, no. 1, pp. 6-13, 2010.

[38] Th. Arampatzis, J. Lygeros, and S. Manesis, "A survey of applications of wireless sensors and wireless sensor networks," in Intelligent Control, 2005. Proceedings of the 2005 IEEE International Symposium on, Mediterrean Conference on Control and Automation, June 2005, pp. 719-724. 